\title{
The safety and efficacy of ERCP in the pediatric population with standard scopes: Does size really matter?
}

\author{
Abdullah Emre Yıldırım ${ }^{1 *}$, Reskan Altun ${ }^{1}$, Serkan Ocal' ${ }^{1}$, Murat Kormaz' ${ }^{1}$ Figen Ozcay ${ }^{2}$ and Haldun Selcuk ${ }^{1}$
}

\begin{abstract}
Experience with endoscopic retrograde cholangiopancreatography in the pediatric population is limited. The aim of this study was to evaluate the outcomes of ERCP in the pediatric population performed by adult gastroenterologists with standard duodenoscopes. This study is a structured retrospective review of endoscopic reports, computerized and paper medical records, and radiographic images of patients under the age of 18 who underwent ERCP for any indication at a tertiary referral centre. Data regarding demographic characteristics and medical history of patients, indications, technical success rate, final clinical diagnosis, and complications were analyzed. Forty-eight children with a mean age of 13 years (range 2-17) underwent a total of 65 ERCPs. The indications of ERCP were as follows; suspected choledocholithiasis (55\%), post-liver transplantation anastomotic biliary strictures (21\%), post-surgical bile duct injury (10\%), choledochal cyst (2\%), recurrent or chronic pancreatitis (10\%), and trauma (2\%). The cannulation success rate in the overall procedure was $93.8 \%$. Therapeutic interventions were performed in $70.7 \%$ of patients. Post ERCP pancreatitis was the most common complication occurring in $9.2 \%$ of patients, and no procedure related mortality occurred. When performed by well-trained adult gastroenterologists, the use of endoscopic retrograde cholangiopancreatography with standard duodenoscopes is safe in pediatric population.
\end{abstract}

Keywords: Endoscopic retrograde cholangiopancreatography, Childhood, Duodenoscope, Pediatric ERCP

\section{Background}

Endoscopic retrograde cholangiopancreatography (ERCP) has long been established as an effective diagnostic and therapeutic modality for pancreaticobiliary disorders in the adult population (Adler et al. 2005). In Waye 1976 reported the first successful ERCP in a 3.5-monthold child with cholestasis using a standard duodenoscope (Waye 1976). The use of ERCP in pediatric population was limited; however, since the development of smaller diameter duodenoscopes and accessories in late $80 \mathrm{~s}$, its use has grown considerably (Allendorph et al. 1987; Fox et al. 2000). Experience was limited due to multiple factors, including the relatively low incidence of diseases requiring ERCP in this age group and the impression that

\footnotetext{
${ }^{*}$ Correspondence: draemreyildirim@gmail.com

${ }^{1}$ Department of Gastroenterology, Faculty of Medicine, Başkent

University, 06500 Bahcelievler, Ankara, Turkey

Full list of author information is available at the end of the article
}

the procedure is technically difficult in children. Additionally, the indications and safety of ERCP in children have not been well defined (Hsu et al. 2000).

The aim of the present study was to evaluate the indications, results, and safety of ERCP in pediatric population performed by adult gastroenterologists with standard duodenoscopes.

\section{Methods}

This study is a structured retrospective review of medical records of patients under the age of 18 who underwent ERCP in Baskent University Department of Gastroenterology between 2001 and 2012. This chart and computerbased study was approved by the Baskent University Institutional Review Board.

All procedures were performed by the same gastroenterologists with appropriate training and expertise in ERCP. Procedures were done at the Baskent University Ankara Hospital, a tertiary centre with expertise in

\section{Springer}

(c) 2016 Yıldırım et al. This article is distributed under the terms of the Creative Commons Attribution 4.0 International License (http://creativecommons.org/licenses/by/4.0/), which permits unrestricted use, distribution, and reproduction in any medium, provided you give appropriate credit to the original author(s) and the source, provide a link to the Creative Commons license, and indicate if changes were made. 
Table 1 Patients' demographics

\begin{tabular}{ll}
\hline Gender (\%) & \\
Female & $20(42 \%)$ \\
Male & $28(58 \%)$ \\
Median age (max-min) & $13(2-17)$ \\
ERCP procedures (\%) & \\
Diagnostic & $33(51 \%)$ \\
Therapeutic & $32(49 \%)$ \\
\hline
\end{tabular}

solid organ transplantation and hepatobiliary surgery. Informed written consent was obtained from the legal guardian of the patients. All patients were placed under deep sedation by an anesthesiologist and the procedures were performed in the prone position.

For all patients, a diagnostic adult duodenoscope (TJF160; Olympus America Corp., Melville, NY, USA) with an insertion diameter of $10.8 \mathrm{~mm}$ or a therapeutic duodenoscope (TJF-100; Olympus America Corp., Melville, NY, USA) with an insertion diameter of $12.5 \mathrm{~mm}$ was used at the discretion of the gastroenterologist. Technical success was defined as a successful deep cannulation of the bile duct or pancreatic duct along with completion of any planned diagnostic or therapeutic procedure. Cannulation was achieved using a tapered tip cannulation catheter with a guidewire. Sphincterotomy was performed in standard fashion. Stone removal was achieved using the passage of Fogarty-type balloon. Ductal clearance was documented with balloon occlusion cholangiogram. For patients in whom ductal clearance was not achieved, a plastic biliary stent was placed in the standard fashion.

Complications were defined as occurring within 2 weeks of the procedure and were further categorized as bleeding (in which endoscopic therapy and/or blood transfusion was required), perforation, post-ERCP pancreatitis, cholangitis, abdominal pain in the absence of cholangitis and/or pancreatitis, and death.

Data regarding demographic characteristics and medical history of patients, indications, technical success rate, final clinical diagnosis, ERCP interventions performed, and complications were obtained from the hospital electronic medical records database and retrospectively analyzed.

IBM SPSS Statistics 19 (SPSS, Inc., Chicago, IL, USA) program was used for statistical analysis. Results were presented as median (minimum-maximum) and percentages.

\section{Results}

Over the 10-year study period, 65 ERCPs were performed, including 33 (51\%) diagnostic and 32 (49\%) therapeutic procedures on 48 children at our institution. There were 20 (42\%) girls and 28 (58 \%) boys aged from 2 to 17 years. The median age was 13 years (2-17 years). Also, $42 \%(\mathrm{n}=20)$ were pre-adolescence and $48 \%$ $(\mathrm{n}=28)$ were teenagers. The majority of the patients $(\mathrm{n}=37)$ underwent a single procedure, 7 underwent two procedures, 3 underwent three procedures and 1 underwent five procedures (Table 1).

Of all procedures, $91 \%$ were for biliary and $9 \%$ for pancreatic indications. The biliary indications were suspected choledocholithiasis (55\%), post liver transplantation anastomotic biliary strictures $(21 \%)$, post-surgical bile duct injury (10\%), and choledochal cyst (2\%). The pancreatic indications included recurrent or chronic pancreatitis (10\%) and trauma (2\%). The final diagnoses after the procedure are demonstrated in Table 2. A normal cholangiography was found in $22.9 \%$ of ERCPs.

An overall procedure, papilla cannulation success rate was $93.8 \%$. Cannulation success rate per patient was $91.7 \%$ (44 of 48 patients). Of these 44 patients, $93.2 \%$ resulted in successful cannulation in first ERCP procedure and $6.8 \%$ in second procedure. Additionally, successful cannulation was achieved $88.6 \%$ (39 of 44 patients) with standard cannulation techniques. In five patients (11.4\%), pre-cut sphincterotomy (with needle-knife in 1 patient and standard sphincterotome in 4 patients) was performed when standard techniques fail to achieve cannulation (Table 3).

Therapeutic interventions were performed in $70.7 \%$ of patients including sphincterotomy in 38 patients $(58.5 \%)$, balloon sweep in 17 patients (26.1\%), biliary plastic stent insertion 12 patients (18.5\%), stone extraction in 8 patients $(12.3 \%)$, nasobiliary drainage tube placement in 6 patients $(9.2 \%)$, and balloon dilatation of biliary strictures in 1 patient (1.5\%) (Table 4).

The complication rate was $12.3 \%$ (8 of 65 procedures) per procedure and $16.6 \%$ (8 of 48 patients) per patients. Complications are summarized in Table 5. Post ERCP pancreatitis was the most common complication, with an occurrence rate of in $9.2 \%$. All six patients were graded as mild pancreatitis according to the consensus classification of post-ERCP pancreatitis by Cotton et al. (1991), and all resolved with conservative treatment. Bleeding occurred in 2 patients (3.1\%) and controlled with endoscopic management. Delayed hemorrhage did not occur. No severe pancreatitis, bleeding, perforation and infection occurred. There was no procedure related mortality.

\section{Discussion}

In present study, the rate of technical success and the rate of complications found in pediatric ERCP were in concordance with previously reported large series (Cheng et al. 2005; Giefer and Kozarek 2015; Enestvedt et al. 
Table 2 Final diagnosis after ERCP

\begin{tabular}{lc}
\hline & $\mathbf{n}(\%)$ \\
\hline Choledocholithiasis & $12(25 \%)$ \\
Post-liver transplantation biliary strictures & $11(22.9 \%)$ \\
Normal & $11(22.9 \%)$ \\
Post-surgical bile duct injury & $3(6.2 \%)$ \\
Biliary strictures & $2(4.1 \%)$ \\
Pancreas divisium & $2(4.1 \%)$ \\
Choledochal cyst & $1(2.1 \%)$ \\
Chronic pancreatitis & $1(2.1 \%)$ \\
Pancreatic duct injury & $1(2.1 \%)$ \\
Unsuccessful ERCP & $4(8.4 \%)$ \\
\hline
\end{tabular}

Table 3 ERCPs success, cannulation properties and techniques rates

\begin{tabular}{lrll}
\hline & N & $\%$ \\
\hline Overall ERCP procedures, papilla cannulation success & 61 & $93.8(61 / 65)$ \\
Cannulation success rate per patients & 44 & $91.7(44 / 48)$ \\
Successful cannulation in first ERCP procedure & 41 & $93.2(41 / 44)$ \\
Successful cannulation in second ERCP procedure & 3 & $6.8(3 / 44)$ \\
$\begin{array}{l}\text { Successful cannulation with standard cannulation } \\
\text { techniques }\end{array}$ & 39 & $88.6(39 / 44)$ \\
$\begin{array}{l}\text { Successful cannulation with precut sphincterotomy } \\
\text { techniques }\end{array}$ & 5 & $11.4(5 / 44)$ \\
\hline
\end{tabular}

2013; Troendle and Barth 2013, 2015; Halvorson et al. 2013; Otto et al. 2011; Jang et al. 2010; Iqbal et al. 2009) (Table 6). We suggest that ERCP is a safe and effective method for both the diagnosis and treatment of pediatric patients.

When performed by experienced endoscopists, ERCP has an acceptable complication rate in the adult population (Rabenstein et al. 1999). In the pediatric population, experience with ERCP has been limited due to multiple factors including a relatively low incidence of diseases requiring ERCP and the impression that the procedure is technically difficult in children. Additionally, the indications and safety of ERCP in the pediatric population have not been well defined. Few pediatric gastroenterologists receive sufficient training on advanced endoscopy including procedures such as ERCP. This gap is generally filled by adult gastroenterologists.

The main problem is that most adult endoscopy units do not have pediatric duodenoscopes. Pediatric duodenoscopes are recommended for children $<10 \mathrm{~kg}$ or younger than 12 months of age, beyond which an adult diagnostic or therapeutic duodenoscope is acceptable (ASGE Technology Committee et al. 2012). However, a diagnostic duodenoscope or a therapeutic duodenoscope
Table 4 Therapeutic interventions (65 procedures in 48 patients)

\begin{tabular}{lc}
\hline & n (\%) \\
\hline Sphincterotomy & $38(58.5 \%)$ \\
Balloon sweep & $17(26.1 \%)$ \\
Biliary plastic stent insertion & $12(18.5 \%)$ \\
Stone extraction & $8(12.3 \%)$ \\
Nasobiliary drainage tube placement & $6(9.2 \%)$ \\
Ballon dilatation of biliary strictures & $1(1.5 \%)$ \\
\hline
\end{tabular}

Table 5 Complications related to ERCP

\begin{tabular}{lll}
\hline & N & \% of total ERCP \\
\hline Post ERCP pancreatits & 6 & 9.2 \\
Bleeding after sphincterotomy & 2 & 3.1 \\
Total & 8 & 12.3 \\
\hline
\end{tabular}

was used at the discretion of the gastroenterologist in this study, and no complications such as tracheal impressions, airway obstruction, nor the necessity of endotracheal intubation occurred.

In Western countries, the most common indications for ERCP are choledocholithiasis and acute or chronic pancreatitis whereas the most frequent indication in Eastern countries (Japan, Korea and India) is congenital choledochal cysts (Cheng et al. 2005; Pfau et al. 2002; Teng et al. 2000; Issa et al. 2007; Jang et al. 2010; Otto et al. 2011). The most common indication in this study was choledocholithiasis. Additionally because of Baskent University hospital is a tertiary centre with expertise in solid organ transplantation, post-liver transplantation biliary strictures had a similar frequency. Enestvedt et al. reported their pediatric ERCP experience in 296 children who underwent a total of 429 ERCPs. The most common indications in this series were similar to present study such as choledocholithiasis $(26.1 \%)$ and biliary stricture (26.1 \%) (Enestvedt et al. 2013).

Conscious or deep sedation and topical anesthesia has become a safe alternative to general anesthesia in pediatric endoscopy (Green et al. 2001). But the higher complexity and duration of the procedure in pediatric patients with a smaller anatomy sometimes requires general anesthesia. Although the many therapeutic interventions were applied to our pediatric patients and the youngest patient was 2 years old, none of our patients required general anesthesia. Conscious or deep sedation were preferred for all patients unlike other pediatric series (Cheng et al. 2005; Paris et al. 2010; Halvorson et al. 2013; Troendle and Barth 2013). There were also no 
Table 6 Pediatric endoscopic retrograd cholangiopancreatography larger series

\begin{tabular}{|c|c|c|c|c|c|c|c|}
\hline References & Mean age (range) & Study design & Endoscopist & Patient (n) & $\operatorname{ERCP}(n)$ & $\begin{array}{l}\text { Procedure } \\
\text { success (\%) }\end{array}$ & Therapeutic (\%) \\
\hline $\begin{array}{l}\text { Giefer and Kozarek } \\
\text { (2015) }\end{array}$ & $\begin{array}{l}13.6 \text { years } \\
(2 \text { months-18 years) }\end{array}$ & Retrospective & Adult & 276 & 425 & 95 & 81 \\
\hline Troendle et al. (2015) & $\begin{array}{l}12.7 \text { years } \\
(1 \text { months-19 years })\end{array}$ & Retrospective & $\begin{array}{l}\text { Pediatric } \\
\text { and adult }\end{array}$ & 313 & 432 & NR & 86 \\
\hline Enestvedt et al. (2013) & $\begin{array}{l}14.9 \text { years } \\
(3 \text { months- } 21 \text { years })\end{array}$ & Retrospective & Adult & 296 & 429 & 95 & 64 \\
\hline Halvorson et al. (2013) & 12 years (6 years -17 years) & Retrospective & Adult & 45 & 70 & 99 & 93 \\
\hline $\begin{array}{l}\text { Troendle and Barth } \\
\text { (2013) }\end{array}$ & $\begin{array}{l}15.2 \text { years } \\
(1 \text { months-18.4 years })\end{array}$ & Retrospective & Pediatric & 65 & 154 & 100 & 100 \\
\hline Otto et al. (2011) & $\begin{array}{l}11.4 \text { years } \\
\text { ( } 2 \text { months-21 years) }\end{array}$ & Retrospective & Adult & 167 & 231 & NR & 69 \\
\hline Jang et al. (2010) & 8 years (1 months- 16 years) & Retrospective & Pediatric & 122 & 245 & 98 & 78 \\
\hline lqbal et al. (2009) & NR & Retrospective & Adult & 224 & 343 & NR & 43 \\
\hline Cheng et al. (2005) & $\begin{array}{l}9.3 \text { years } \\
(1 \text { months }-17 \text { years })\end{array}$ & Retrospective & Adult & 245 & 329 & 98 & 71 \\
\hline
\end{tabular}

NR not specifically reported

serious adverse events such as cardiorespiratory suppression specifically related to deep sedation. These findings suggest that the preference between deep sedation and general anesthesia can be determined according to many factors including patient age, weight, and experience.

The most difficult aspect of the ERCP is the first step: selective biliary cannulation (SBC) which may often end in failure. The principles of SBC in children are similar to those used in adult patients. There are some limitations in pediatric patients such as phenotypic characteristics of age range and equipment sizes. Despite all disadvantages, the rate of successful cannulation is as good as comparable to reports in adults (Allendorph et al. 1987; Guelrud et al. 1994; Otto et al. 2011). Success rates of pediatric ERCP were reported $89.5-100 \%$ in previous studies (Teng et al. 2000; Paris et al. 2010; Green et al. 2007; Cheng et al. 2005; Giefer and Kozarek 2015; Enestvedt et al. 2013). The success rate in this study is similar to those in previous reports. Cannulation was unsuccessful in four patients, all of whom were younger than five. The diameter of the ERCP catheter and the sphincterotome is larger than the diameter of the papilla. In our experience, this diameter mismatch increases the difficulty of achieving selective bile duct cannulation in small children and infants.

There were a remarkable amount of therapeutic interventions $(70.7 \%)$ in this pediatric patient series. In most of the procedures, more than one intervention was performed including sphincterotomy with balloon sweep or sphincterotomy or balloon sweep with subsequent biliary plastic stent insertion.

The overall complication rate found in the present study $(12.3 \%)$ reflected the findings found in literature with regard to adult and pediatric patients $(1 \%-17,5 \%)$
(Allendorph et al. 1987; Cotton et al. 1991; Cheng et al. 2005; Pfau et al. 2002; Teng et al. 2000; Paris et al. 2010; Halvorson et al. 2013; Enestvedt et al. 2013). Post-ERCP pancreatitis, the most common ERCP-related complication in children, was found to occur in $9.2 \%$ of total ERCP in this study, which is similar to the incidence typically reported in early series (3-17 \%) (Fox et al. 2000). Cheng et al. reported that the rate of pancreatitis after therapeutic ERCP was higher than diagnostic ERCP (11.1 vs $5.4 \%$, respectively) (Cheng et al. 2005). The occurrence of pancreatitis in our patient population may be associated with the high rate of therapeutic interventions. The reported incidence of other complications are as follows; hemorrhage $1-4 \%$, perforation $1-2 \%$, and cholangitis 1-5 \% (Freeman et al. 1996; Masci et al. 2001; Feurer and Adler 2012; Vandervoort et al. 2002; Wang et al. 2009). Post-ERCP complication rates vary widely depending on the complexity of the intervention.

This study has several limitations that should be noted. First, it is retrospective nature. Complete medical reports such as weight and BMI percentile of the pediatric patients were not available on all patients. Because of the fact that our facility was a referral centre, followup was shorter than 30 days. Short follow-ups consequently led to limited information retrieval on the effect of post ERCP in survival, late complications, and recurrence of the presenting disease. It is a single-center study from a tertiary referral centre. Therefore, the outcomes of this study cannot be generalized as these factors can vary based on local referral patterns, pre/peri/post-procedural medical care, and endoscopist experience.

Based on the results of our study, we suggest that diagnostic and therapeutic ERCP is safe and effective in the 
pediatric population when performed by an experienced adult gastroenterologist at high-volume centers. The complication rates are comparable to those that observed in adults.

\section{Authors' contributions}

Concept: AEY, RA; Design: AEY, RA, SO; Supervision: AEY, RA, MK, H.S; Resource: AEY, RA, SO; Materials: AEY, RA, SO, FÖ; Data Collection and/or Processing: AEY, SO, FO; Analysis and/or Interpretation: AEY, RA, MK; Literature Search: AEY, RA, SO, MK, HS; Writing: AEY, RA, SO; Critical Reviews: RA, MK, HS. All authors read and approved the final manuscript.

\section{Author details}

'Department of Gastroenterology, Faculty of Medicine, Başkent University, 06500 Bahcelievler, Ankara, Turkey. ${ }^{2}$ Department of Pediatric Gastroenterology, Faculty of Medicine, Başkent University, Ankara, Turkey.

\section{Competing interests}

The authors declare that they have no competing interests.

Received: 10 January 2016 Accepted: 12 February 2016

Published online: 19 February 2016

\section{References}

Adler DG, Baron TH, Davila RE, Egan J, Hirota WK, Leighton JA, Qureshi W, Rajan E, Zuckerman MJ, Fanelli R, Wheeler-Harbaugh J, Faigel DO (2005) ASGE guideline: the role of ERCP in diseases of the biliary tract and the pancreas. Gastrointest Endosc 62(1):1-8

Allendorph M, Werlin SL, Geenen JE, Hogan WJ, Venu RP, Stewart ET, Blank EL (1987) Endoscopic retrograde cholangiopancreatography in children. J Pediatr 110(2):206-211

ASGE Technology Committee, Barth BA, Banerjee S, Bhat YM, Desilets DJ, Gottlieb KT, Maple JT, Pfau PR, Pleskow DK, Siddiqui UD, Tokar JL, Wang A, Song LM, Rodriguez SA (2012) Equipment for pediatric endoscopy. Gastrointest Endosc 76(1):8-17

Cheng CL, Fogel EL, Sherman S, McHenry L, Watkins JL, Croffie JM, Gupta SK, Fitzgerald JF, Lazzell-Pannell L, Schmidt S, Lehman GA (2005) Diagnostic and therapeutic endoscopic retrograde cholangiopancreatography in children: a large series report. J Pediatr Gastroenterol Nutr 41(4):445-453

Cotton PB, Lehman G, Vennes J, Geenen JE, Russell RC, Meyers WC, Liguory C, Nickl N (1991) Endoscopic sphincterotomy complications and their management: attempt at consensus. Gastrointest Endosc 37(3):383-393

Enestvedt BK, Tofani C, Lee DY, Abraham M, Shah P, Chandrasekhara V, Ginsberg GG, Long W, Ahmad N, Jaffe DL, Mamula P, Kochman ML (2013) Endoscopic retrograde cholangiopancreatography in the pediatric population is safe and efficacious. J Pediatr Gastroenterol Nutr 57(5):649-654

Feurer ME, Adler DG (2012) Post-ERCP pancreatitis: review of current preventive strategies. Curr Opin Gastroenterol 28(3):280-286

Fox VL, Werlin SL, Heyman MB (2000) Endoscopic retrograde cholangiopancreatography in children. J Pediatr Gastroenterol Nutr 30(3):335-342

Freeman ML, Nelson DB, Sherman S, Haber GB, Herman ME, Dorsher PJ, Moore JP, Fennerty MB, Ryan ME, Shaw MJ, Lande JD, Pheley AM (1996) Complications of endoscopic biliary sphincterotomy. N Engl J Med 335:909-918

Giefer MJ, Kozarek RA (2015) Technical outcomes and complications of pediatric ERCP. Surg Endosc 29(12):3543-3550
Green SM, Klooster M, Harris T, Lynch EL, Rothrock SG (2001) Ketamine sedation for pediatric gastroenterology procedures. J Pediatr Gastroenterol Nutr 1:26-33

Green JA, Scheeres DE, Conrad HA, Cloney DL, Schlatter MG (2007) Pediatric ERCP in a multidisciplinary community setting: experience with a fellowship-trained general surgeon. Surg Endosc 21(12):2187-2192

Guelrud M, Mujica C, Jaen D, Plaz J, Arias J (1994) The role of ERCP in the diagnosis and treatment of idiopathic recurrent pancreatitis in children and adolescents. Gastrointest Endosc 40(4):428-436

Halvorson L, Halsey K, Darwin P, Goldberg E (2013) The safety and efficacy of therapeutic ERCP in the pediatric population performed by adult gastroenterologists. Dig Dis Sci 58(12):3611-3619

Hsu RK, Draganov P, Leung JW, Tarnasky PR, Yu AS, Hawes RH, Cunningham JT, Cotton PB (2000) Therapeutic ERCP in the management of pancreatitis in children. Gastrointest Endosc 51(4 Pt 1):396-400

lqbal CW, Baron TH, Moir CR, Ishitani MB (2009) Post-ERCP pancreatitis in pediatric patients. J Pediatr Gastroenterol Nutr 49(4):430-434

Issa H, Al-Haddad A, Al-Salem AH (2007) Diagnostic and therapeutic ERCP in the pediatric age group. Pediatr Surg Int 23(2):111-116

Jang JY, Yoon CH, Kim KM (2010) Endoscopic retrograde cholangiopancreatography in pancreatic and biliary tract disease in Korean children. World J Gastroenterol 16(4):490-495

Masci E, Toti G, Mariani A, Curioni S, Lomazzi A, Dinelli M, Minoli G, Crosta C, Comin U, Fertitta A, Prada A, Passoni GR, Testoni PA (2001) Complications of diagnostic and therapeutic ERCP: a prospective multicenter study. Am J Gastroenterol 96(2):417-423

Otto AK, Neal MD, Slivka AN, Kane TD (2011) An appraisal of endoscopic retrograde cholangiopancreatography for pancreaticobiliary disease in children: our institutional experience in 231 cases. Surg Endosc 25(8):2536-2540

Paris C, Bejjani J, Beaunoyer M, Ouimet A (2010) Endoscopic retrograde cholangiopancreatography is useful and safe in children. J Pediatr Surg 45(5):938-942

Pfau PR, Chelimsky GG, Kinnard MF, Sivak MV Jr, Wong RC, Isenberg GA, Gurumurthy P, Chak A (2002) Endoscopic retrograde cholangiopancreatography in children and adolescents. J Pediatr Gastroenterol Nutr 35(5):619-623

Rabenstein T, Schneider HT, Nicklas M, Ruppert T, Katalinic A, Hahn EG, Ell C (1999) Impact of skill and experience of the endoscopist on the outcome of endoscopic sphincterotomy techniques. Gastrointest Endosc 50(5):628-636

Teng R, Yokohata K, Utsunomiya N, Takahata S, Nabae T, Tanaka M (2000) Endoscopic retrograde cholangiopancreatography in infants and children. J Gastroenterol 35(1):39-42

Troendle DM, Barth BA (2013) ERCP can be safely and effectively performed by a pediatric gastroenterologist for choledocholithiasis in a pediatric facility. J Pediatr Gastroenterol Nutr 57(5):655-658

Troendle DM, Abraham O, Huang R, Barth BA (2015) Factors associated with post-ERCP pancreatitis and the effect of pancreatic duct stenting in a pediatric population. Gastrointest Endosc 81(6):1408-1416

Vandervoort J, Soetikno RM, Tham TC, Wong RC, Ferrari AP Jr, Montes H, Roston AD, Slivka A, Lichtenstein DR, Ruymann FW, Van Dam J, Hughes M, Carr-Locke DL (2002) Risk factors for complications after performance of ERCP. Gastrointest Endosc 56(5):652-656

Wang P, Li ZS, Liu F, Ren X, Lu NH, Fan ZN, Huang Q, Zhang X, He LP, Sun WS, Zhao Q, Shi RH, Tian ZB, Li YQ, Li W, Zhi FC (2009) Risk factors for ERCPrelated complications: a prospective multicenter study. Am J Gastroenterol 104(1):31-40

Waye JD (1976) Endoscopic retrograde cholangiopancreatography in the infant. Am J Gastroenterol 65(5):461-463 